\title{
Anger management: bacteria soothe the savage host
}

\author{
Patrick C. Seed, MD, PhD \\ Department of Pediatrics-Infectious Diseases, Department of Molecular Genetics and Microbiology, and Department of Surgery-Urology, \\ Duke University School of Medicine, Durham, North Carolina, USA.
}

\begin{abstract}
A 5-year-old girl has come to you a week after completing a course of antibiotics for a febrile urinary tract infection (UTI). She now seems well and energetic. A urinalysis is now clear without traces of inflammation, including an absence of protein, blood, leukocyte esterase, and nitrites. Her urine is submitted for a test of cure and comes back positive, with over 100,000 colonies per milliliter of $E$. coli, the same kind of bacteria that was cultured from her urine when she was symptomatic with the UTI. Perplexed, her mother asks how her child can have bacteria once again in her bladder but not be symptomatic and asks if antibiotics are again necessary.
\end{abstract}

\section{Current therapy}

Urinary tract infection (UTI) is one of the most common infections in humans, accounting for over 10 million infections per year with an estimated $\$ 3$ billion in costs (1). While the urinary tract is typically regarded as sterile, the diagnosis of UTI is complicated by a sizable minority group of $1 \%$ to $5 \%$ of women and children who are colonized with bacteria in the urinary bladder, but who do not have the symptoms and signs of UTI, so-called asymptomatic bacteriuira (ASB) (2). ASB yet further increases in prevalence among individuals with neurogenic bladders, the elderly, and those in nursing facilities, particularly those with some type of bladder catheterization, in whom the frequency may exceed $50 \%$ of the population (3). A hallmark of ASB is the absence of inflammation in the urinary tract, suggesting that the bacteria involved in ASB are able to colonize without inducing a host response. It is the inflammatory response of the host that produces the characteristic features of UTI, such as burning and pain with urination, urinary urgency, and sometimes fever.

Although tempting, treatment is not warranted in most individuals with ASB, with few exceptions such as pregnancy and anatomic or immunological defects. In general, the treatment of ASB with antibiotics has been shown to result in the emer-

Conflict of interest: The author has declared that no conflict of interest exists.

Citation for this article: J Clin Invest. 2013; 123(6):2348-2349. doi:10.1172/JCI69647. gence of antibiotic-resistant bacteria without the clinical benefit of reduced future episodes of UTI $(4,5)$. For this reason, routine screening of urine for asymptomatic colonization is generally not indicated.

\section{Knowledge gap}

A major clinical problem, particularly in an era of rapidly rising antimicrobial resistance, is to distinguish between UTI and ASB, sparing antibiotics when not needed. Interestingly, the rise of antibiotic resistance, combined with benign behavior of ASB bacteria in the urinary tract, have fueled interest in turning ASB strains into therapeutics, thus capitalizing on the capacity of ASB bacteria to colonize without aggravating the host and to outcompete more pathogenic strains. Thus, the mechanisms by which ASB bacteria are so uniquely adapted to a commensal lifestyle have been of great interest.

ASB bacteria, which are predominantly strains of E. coli, have robust growth characteristics, even in nutrient-deficient conditions such as in urine $(6,7)$. Furthermore, ASB E. coli are known to have the capacity to outcompete uropathogenic E. coli in growth and adherence to abiotic surfaces such as catheters, as well as biotic surfaces such as epithelial cells (8). Taking advantage of these characteristics, a number of investigators have pioneered the use of specific ASB strains in high-risk patient populations, such as those with neurogenic bladders and indwelling catheters. Prior work using E. coli 83972, an ASB strain that was isolated from a young child with over 3 years of persistent colonization without renal deterioration, demonstrated that slightly over $60 \%$ of adults with spinal cord injury and neurogenic bladder could be persistently colonized with the strain (9). Of those colonized, $60 \%$ were UTI-free by 1 year after colonization, while $10 \%$ of the controls were UTI-free at 1 year.

While past studies suggest that ASB E. coli do, in fact, outcompete uropathogenic E. coli strains, providing an explanation for why they prevent UTI by uropathogenic isolates, it has been less clear why the ASB strains do not themselves cause inflammation like the uropathogenic strains. Comparative genomic studies suggest that ASB E. coli strains have evolved from more archetypal uropathogenic strains, with genome reduction resulting in the attrition of loci that encode virulence determinants. However, this alone does not explain why factors such as lipopolysaccharides, shared by ASB and pathogenic strains alike, do not equally stimulate host inflammatory cascades.

\section{Research advances}

In this issue of the JCI, Lutay et al. (10) provide an exciting and novel explanation. The authors demonstrate that in the course of human inoculation with ASB E. coli, the bacteria block the phosphorylation of RNA polymerase II (RNA Pol II), which is typically phosphorylated following uropathogenic E. coli interaction with urinary tract epithelial cells. By doing so, the ASB strains broadly reprogram the target host cell's response to the bacteria-host interaction with the suppression of transcriptional regulatory pathways, cellular proliferation and remodeling pathways, and innate immune pathways such as IRF3, IRF7, and AP1 originating from the Tolllike receptor 4 (TLR4). These ASB strains further demonstrate that the RNA Pol II mechanism of suppression holds true for a wide variety of ASB and fecal commensal E. coli, while uropathogenic strains generally do not possess this capacity. 


\section{Recommendations}

The immediate impact of this work lies within the concept of using ASB strains as therapeutics in difficult patient populations that have a lifetime of recurrent UTIs and thus high antibiotic exposure. These include individuals with spinal cord injury and other forms of neurogenic bladder. Because these individuals may develop renal and bladder fibrosis with deterioration in function over time, the UTI-blocking capacity of ASB strains as well as their antiinflammatory properties remain intriguing. ASB strains may also have the ability to attenuate UTI-associated pain, as suggested by recent work (11).

In the broader view, the fundamental mechanisms of bacterial inhibition of RNA Pol II activation may provide one explanation for how bacteria densely inhabit our mucosal surfaces without driving inflammation and how a loss of this suppression may tilt the balance toward mucosal inflammatory diseases, which in turn may have long-term immune and allergic consequences. Conditions such as inflammatory bowel disease $(12,13)$, irritable bowel syndrome (14), necrotizing enterocolitis (15), and recurrent bacterial vaginitis (16) are among a number of examples in which commensal bacteria with strong RNA Pol II suppression phenotypes may be beneficial as adjunctive medical therapy. Current medically used probiotics such as lactobacilli and E. coli Nissle 1917 may already have robust RNA Pol II suppression activity, which may be further optimized through the selection of natural derivatives or intentional genetic modifications. Future work will certainly determine the extent to which this mechanism applies and whether it can be harnessed therapeutically as an adjunct in treating inflammatory conditions.

\section{Acknowledgments}

I thank Ravi Jhaveri and Sherry Ross for thoughtful reviews of this manuscript.

Address correspondence to: Patrick C. Seed, Box 3499, DUMC, Durham, North Carolina 27710, USA. Phone: 919.684.9590; Fax: 919.681.2089; E-mail: patrick.seed@ duke.edu.

1. Foxman B. The epidemiology of urinary tract infection. Nat Rev Urol. 2010;7(12):653-660.

2. Colgan R, Nicolle LE, McGlone A, Hooton TM. Asymptomatic bacteriuria in adults. Am Fam Physician. 2006;74(6):985-990.

3. Nicolle LE. Asymptomatic bacteriuria in the elderly. Infect Dis Clin North Am. 1997;11(3):647-662.

4. Nicolle LE, Mayhew WJ, Bryan L. Prospective randomized comparison of therapy and no therapy for asymptomatic bacteriuria in institutionalized elderly women. Am J Med. 1987;83(1):27-33.

5. Nicolle LE, et al. Infectious Diseases Society of America guidelines for the diagnosis and treatment of asymptomatic bacteriuria in adults. Clin Infect Dis. 2005;40(5):643-654.

6. Roos V, Ulett GC, Schembri MA, Klemm P. The asymptomatic bacteriuria Escherichia coli strain
83972 outcompetes uropathogenic E. coli strains in human urine. Infect Immun. 2006;74(1):615-624.

7. Vejborg RM, de Evgrafov MR, Phan MD, Totsika M, Schembri MA, Hancock V. Identification of genes important for growth of asymptomatic bacteriuria Escherichia coli in urine. Infect Immun. 2012;80(9):3179-3188.

8. Klemm P, Hancock V, Schembri MA. Mellowing out: adaptation to commensalism by Escherichia coli asymptomatic bacteriuria strain 83972. Infect Immun. 2007;75(8):3688-3695.

9. Darouiche RO, Thornby JI, Cerra-Stewart C, Donovan WH, Hull RA. Bacterial interference for prevention of urinary tract infection: a prospective, randomized, placebo-controlled, double-blind pilot trial. Clin Infect Dis. 2005;41(10):1531-1534.

10. Lutay N, et al. Bacterial control of host gene expression through RNA polymerase II. J Clin Invest. 2013;123(6):2366-2379.

11. Rudick CN, Billips BK, Pavlov VI, Yaggie RE, Schaeffer AJ, Klumpp DJ. Host-pathogen interactions mediating pain of urinary tract infection. J Infect Dis. 2010;201(8):1240-1249.

12. Kruis W, et al. Maintaining remission of ulcerative colitis with the probiotic Escherichia coli Nissle 1917 is as effective as with standard mesalazine. Gut. 2004;53(11):1617-1623.

13. Rahimi R, et al. A meta-analysis on the efficacy of probiotics for maintenance of remission and prevention of clinical and endoscopic relapse in Crohn's disease. Dig Dis Sci. 2008;53(9):2524-2531.

14. Nikfar S, Rahimi R, Rahimi F, Derakhshani $\mathrm{S}$, Abdollahi M. Efficacy of probiotics in irritable bowel syndrome: a meta-analysis of randomized, controlled trials. Dis Colon Rectum. 2008;51(12):1775-1780.

15. Lin $\mathrm{HC}$, et al. Oral probiotics prevent necrotizing enterocolitis in very low birth weight preterm infants: a multicenter, randomized, controlled trial. Pediatrics. 2008;122(4):693-700.

16. Ya W, Reifer C, Miller LE. Efficacy of vaginal probiotic capsules for recurrent bacterial vaginosis: a double-blind, randomized, placebo-controlled study. Am J Obstet Gynecol. 2010;203(2):120.e1-120.e6. 